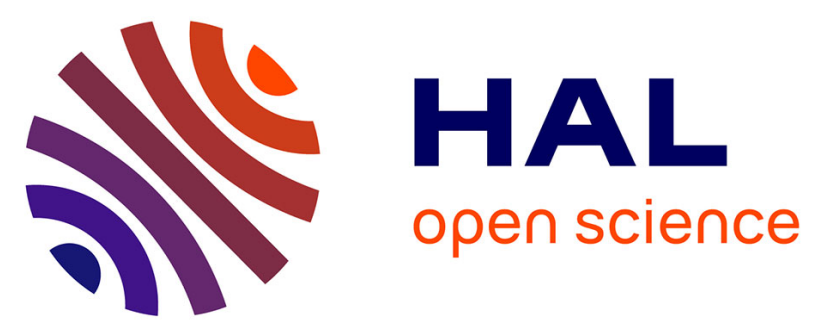

\title{
Improving mesocosm data analysis through individual-based modelling of control population dynamics : a case study with mosquitofish (Gambusia holbrooki)
}

Rémy Beaudouin, Vincent Ginot, Gilles Monod

\section{To cite this version:}

Rémy Beaudouin, Vincent Ginot, Gilles Monod. Improving mesocosm data analysis through individual-based modelling of control population dynamics : a case study with mosquitofish (Gambusia holbrooki). Ecotoxicology, 2012, 21 (1), pp.155-164. 10.1007/s10646-011-0775-1 . ineris-00963354

HAL Id: ineris-00963354

https://hal-ineris.archives-ouvertes.fr/ineris-00963354

Submitted on 29 May 2020

HAL is a multi-disciplinary open access archive for the deposit and dissemination of scientific research documents, whether they are published or not. The documents may come from teaching and research institutions in France or abroad, or from public or private research centers.
L'archive ouverte pluridisciplinaire HAL, est destinée au dépôt et à la diffusion de documents scientifiques de niveau recherche, publiés ou non, émanant des établissements d'enseignement et de recherche français ou étrangers, des laboratoires publics ou privés. 


\title{
Improving mesocosm data analysis through individual-based modelling of control population dynamics: a case study with mosquitofish (Gambusia holbrooki)
}

\author{
Rémy Beaudouin • Vincent Ginot ${ }^{1} \bullet$ Gilles Monod \\ INRA, UR1037 SCRIBE, F-35042 Rennes, France \\ INRA, UR546 Biométrie, F-84814 Avignon, France \\ INERIS, Unité METO, F-60550 Verneuil en Halatte, France \\ Rémy Beaudouin $(\square)$ : \\ INERIS, Unité METO, F-60550 Verneuil en Halatte, France \\ Tél.: + 33344618238 \\ Fax : + 33344556800 \\ Email: remy.beaudouin@ineris.fr \\ Abstract
}

Experimental ecosystems such as mesocosms have been developed to improve the ecological relevance of ecotoxicity test. However, in mesocosm studies, the number of replicates is limited by practical and financial constraints. In addition, high levels of biological organization are characterized by a high variability of descriptive variables. This variability and the poor number of replicates have been recognized as a major drawback for detecting significant effects of chemicals in mesocosm studies. In this context, a tool able to predict precisely control mesocosms outputs, to which endpoints in mesocosms exposed to chemicals could be compared should constitute a substantial improvement. We evaluated here a solution which consists in stochastic modelling of the control fish populations to assess the probabilistic distributions of population endpoints. An individual-based approach was selected, because it generates realistic fish length distributions and accounts for both individual and environmental sources of variability. This strategy was applied to mosquitofish (Gambusia holbrooki) populations monitored in lentic mesocosms. We chose the number of founders as a so-called "stressor" because subsequent consequences at the population level could be expected. Using this strategy, we were able to detect more significant and biologically relevant perturbations than using classical methods. We conclude that designing an individual-based model is very promising for improving mesocosm data analysis. This methodology is currently being applied to ecotoxicological issues.

Keywords Individual-based model; Mesocosm; Fish population; Ecotoxicity; Data analysis

\footnotetext{
${ }^{1}$ Vincent Ginot passed away before this manuscript was finished
} 


\section{Introduction}

Outdoor experimental aquatic ecosystems (mesocosms) have been presented as convenient tools to perform high-tier ecotoxicological studies (i.e. studies performed at the population level or higher). Under these conditions, ecologically relevant levels of biological organization (population, community) can be monitored and it is possible to focus on selected organisms, depending on the question to be addressed (Shaw and Kennedy 1996).

The hazard assessment of chemicals using fish population dynamics in a mesocosm is of great interest since fish are emblematic of the aquatic environment. However, to reduce the time span of mesocosm studies and because mesocosms have limited carrying capacity for fish populations (usually tanks which are a few cubic meters in volume), the study of the impact of chemicals on fish population dynamics in mesocosms should be preferably performed on small fish species exploiting a broad range of trophic resources and having a short life cycle.

The mosquitofish is a live-bearing fish (i.e. ovoviviparous with internal fertilisation) which is a native of the coastal region of southeastern United States (Pyke 2005). During the 20th century, it was widely introduced into warm temperate and tropical regions all over the world, due to mosquito control programs. In this species, male possesses a modified anal fin, the gonopodium, whose state of development indicates the state of its sexual maturity (Dulzetto 1931; Zulian et al. 1995). Furthermore, in males, contrary to females, the onset of sexual maturation is known to coincide with a marked decrease in growth rate (Campton and Gall 1988) and males virtually stop growing after reaching sexual maturity (Zulian et al. 1995; Pyke 2005), hence females grow much larger than males. The mosquitofish population dynamics could be monitored in a mesocosm within a few months (Drèze et al. 1998). Accordingly, mosquitofish have been used for evaluating genetic and demographic responses of fish to pollutants in outdoor lentic mesocosms (Giddings et al. 1984; Tatara et al. 2002).

Studies conducted in mesocosms are generally limited to a few replicates because of limited human, material and financial resources (Kraufvelin 1999). This, together with the high variability that characterizes the higher levels of biological organization, including the population level, has been recognized as a major drawback for detecting significant effects of chemicals, and consequently as a source of false negative results, i.e. concluding a chemical has no effect when it really has (Shaw et al. 1994; Kennedy et al. 1999; Sanderson 2002; de Jong et al. 2005). To increase the statistical power of the mesocosm data analysis, an individual-based model (IBM) of the population dynamics of mosquitofish in mesocosm was previously built, calibrated and validated in order to precisely compute the probabilistic distributions of control population endpoints, including fish length distribution (Beaudouin et al. 2008b). Hence, the probability of exposed population endpoints to be similar to those of the control populations can be calculated.

In the present study, the strategy presented above was tested on a case study. Thus, we compared control mosquitofish populations to populations founded by two and four times more individuals, either by using a few real control populations (as done usually in mesocosm studies) or by using the simulated probabilistic distributions of the endpoints in control conditions predicted by the model. As previously demonstrated (Drèze et al. 1998), when the number of founders is increased the population should more rapidly reach the carrying capacity of the mesocosm, with consequences on population dynamics which could be logically interpreted. 


\title{
Material and methods
}

\author{
Fish \\ Mosquitofish were obtained from the breeding facilities of the "Unité Expérimentale d'Ecologie et \\ d'Ecotoxicologie Aquatique" (U3EA, INRA, Rennes).
}

\section{Mesocosm experiment}

Mesocosms were located at the U3EA. They consisted of circular metal tanks (3.0 $\mathrm{m}$ diameter, $0.6 \mathrm{~m} \mathrm{high}$ ), lined with polyethylene film ( $0.2 \mathrm{~mm}$ thick). In January, a layer of sediment (organic compost) about $2 \mathrm{~cm}$ thick of was introduced into each mesocosm, which were then filled with tap water $(45 \mathrm{~cm}$ depth). The mesocosms were left for natural settlement of phytoplankton, zooplankton and macro-invertebrates. In April, eight plant pots with seven stems of Elodea canadensis each were deposited onto the sediments of each mesocosm. In June, mosquitofish (founder individuals) were introduced into each mesocosm and nets were installed over the mesocosms to protect the fish from bird predation. During the experiment, tap water was added to maintain a constant water depth, and water temperature was recorded every two hours and other physico-chemical parameters (dissolved oxygen concentration and $\mathrm{pH}$ ) were recorded weekly in each mesocosm. No supplementary feeding was given during the experiment beyond the naturally occurring prey. The mosquitofish is an opportunistic omnivore and it exhibits a broad food choice (Walters and Legner 1979; Pyke 2005). Accordingly, during the whole experiment, trophic resources were available to the fish. The experiment was halted in October. The entire population from each mesocosm was collected. Fish were then killed with an overdose of MS222 and then stored in 99\% ethanol until further analysis.

Following this protocol, three control populations (three mesocosms) founded by 6 females and 2 males, two populations (two mesocosms) founded by two times more individuals ( 12 females and 4 males; noted " $\mathrm{N}_{\mathrm{i}} \times 2$ populations") and two populations (two mesocosms) founded by four times more individuals ( 24 females and 8 males; noted " $\mathrm{N}_{\mathrm{i}} \times 4$ populations") were monitored during the same experiment. Before the experiment, the fish had been bred in the same conditions. Female and male length (from snout to insertion of the anal fin) was 29.9 $\pm 3.3 \mathrm{~mm}$ and $22.0 \pm 3.0 \mathrm{~mm}$ before being randomly released into the mesocosms, respectively. The length of the female and the length of the male did not significantly differ between mesocosms. From June to October, females produced several broods (typically four).

\section{Data}

At the end of the experiment, all the fish were measured and sexed. According to our data and to the literature, fish that were $<17 \mathrm{~mm}$ long were classified as juveniles and fish that were $\geq 17 \mathrm{~mm}$ long were sexed as female or male. Males were classified as immature males (gonopodium not fully developed) or mature males (fully developed gonopodium) by observing their anal fin with a stereomicroscope. 


\section{Model}

In our study, we used an individual-based model (IBM) because it produces realistic simulations of fish length frequency distribution, as well as variability between fish individuals and between aquatic environments (mesocosms) (DeAngelis et al. 1979; Grimm and Railsback 2005). Modelling choices, model description, sensitivity analysis, calibration and validation are detailed in Beaudouin et al. (2008b). The variables modelled were those with the main impacts on the population dynamics: a minimal number of variables were integrated in the model to accurately predict real control populations (Beaudouin et al. 2008b). This model description follows the ODD protocol to be transparent and allows replication of the model's implementation (Grimm et al. 2010). The model was calibrated thanks to data from two years of experiments and was successfully validated thanks to control populations which grew during another year. The model provided a probabilistic distribution of the values of each population endpoint (variables describing population size and structure at the end of the experiments) under control conditions. Simulations started with six females and two males, as in the real control populations. The initial length of each of these individuals was drawn from the length frequency distribution of the founder fish measured before their introduction into the mesocosms. The other attributes of founder individuals were either set at the same value as all other individuals or drawn from a probability distribution defined for all individuals (detailed in Beaudouin et al., 2008b). Hence, a random initial population was drawn at the beginning of each simulation, representing a possible real initial population in a real mesocosm. The inputs of the model for the simulation were the mean daily water temperature and the daily photoperiod, the former recorded in the mesocosm, the latter computed from the date of the real experiment. The time step of the model was set to one day and the simulation runs lasted the same amount of time as the real experiments (112 days). The outputs of the model (the variables describing the simulated populations) were the endpoints which were monitored in the real populations. The probabilistic distributions of the control population endpoints were estimated through the simulation of 10,000 populations under the control conditions.

\section{Statistical analysis}

Comparisons of $\mathrm{N}_{\mathrm{i}} \times 2$ and $\mathrm{N}_{\mathrm{i}} \times 4$ populations to control populations were conducted using the non-parametric Mann-Whitney bilateral U-test $(\mathrm{p}<0.05)$. Comparisons of $\mathrm{N}_{\mathrm{i}} \times 2$ and $\mathrm{N}_{\mathrm{i}} \times 4$ populations to the simulated probabilistic distributions of the endpoints in control conditions were conducted using likelihood tests $(p<0.05)$. We both compared scalar outputs (e.g. total number of fish per population) and distribution outputs (e.g. the length frequency distribution). The statistical methods are detailed in the Online Appendix. Statistical analyses were performed using the R statistical environment (R Development Core Team 2009).

\section{Results}

\section{Fish environment}

Table 1 presents the mean and the standard deviation of the physico-chemical parameters recorded in each mesocosm during the experiment. Water temperature was similar between the mesocosms. Dissolved oxygen and $\mathrm{pH}$ were similar between mesocosms except in the mesocosm $\mathrm{N}_{\mathrm{i}} \times 2-1$. In this mesocosm, $\mathrm{pH}$, oxygen saturation and oxygen concentration were lower than in the other mesocosms. Representative views of the 
macrophyte communities which grew in the mescocosms are presented in Figure 1. Elodea canadensis and Spirogyra sp were the main macrophytes observed in the three control mesocosms, the two $\mathrm{N}_{\mathrm{i}} \times 4$ mesocosms and one of the two $\mathrm{N}_{\mathrm{i}} \times 2$ mesocosms (Fig. 1A, B, D). In the other $\mathrm{N}_{\mathrm{i}} \times 2$ mesocosm, Lemna sp. developed on the top of the water and progressively covered the whole surface (Fig. 1C), which prevented the development of the other macrophytes.

\section{Model validation}

The model was built to simulate the dynamics of the mosquitofish population under control conditions, i.e. to simulate the state variables of the control populations of a one year experiment. Accordingly, validation (i.e. establishing how valid a model is for the problem it is intended to solve, Grimm and Railsback, 2005) was performed by testing that the state variables of the control populations simulated by the model were not statically different from the state variables of the real control populations of this study( detailed in Beaudouin et al. (2008b). In this experiment, the test showed that the simulated populations did not differ from the observed populations with regards to both scalar endpoints (Fig. 2) and length frequency distributions (Fig. 7 in Beaudouin et al. 2008b).

\section{Effects of a greater number of founder individuals}

Comparison with the observed control populations. - Comparison between the observed populations (control, $\mathrm{N}_{\mathrm{i}} \times 2$ and $\mathrm{N}_{\mathrm{i}} \times 4$ populations) shows that the increase of the number of founder individuals induced a significant increase of two endpoints $(p<0.05)$ : the number of founder females surviving at the end of the experiment (Fig. 2B) and the mean length of mature males (Fig. 2J).

Comparison with the simulated control populations. - Comparison of the endpoints of the $\mathrm{N}_{\mathrm{i}} \times 2$ and $\mathrm{N}_{\mathrm{i}} \times 4$ populations with the simulated distributions of the scalar endpoints in control conditions shows that five endpoints were significantly different $(\mathrm{p}<0.05)$. The number of founder females surviving at the end of the experiment (Fig. 2B) and the mean length of mature males (Fig. 2J) were significantly higher in the $\mathrm{N}_{\mathrm{i}} \times 2$ and $\mathrm{N}_{\mathrm{i}} \times 4$ populations. These differences were also observed when the comparisons were performed with regard to the three observed control populations. In addition, the coefficient of variation of the juvenile length (Fig. 2N) was significantly higher in the $\mathrm{N}_{\mathrm{i}} \times 2$ populations, while the total number of fish (Fig. 2A) and the mean length of founder females (Fig. 2G) were significantly higher and lower in the $\mathrm{N}_{\mathrm{i}} \times 4$ populations, respectively. Furthermore, differences were observed for length frequency distributions. In the $\mathrm{N}_{\mathrm{i}} \times 2$ and the $\mathrm{N}_{\mathrm{i}} \times 4$ populations, juvenile and male length frequency distributions were significantly different than that simulated by the model in control conditions (Fig. 3A, B, D; p < 0.05). In addition, the female length frequency distribution of the $\mathrm{N}_{\mathrm{i}} \times 4$ populations was also significantly different (Fig. 3C; $p<0.05$ ). Table 2 summarizes the significant differences observed when comparing the $\mathrm{N}_{\mathrm{i}} \times 2$ and $\mathrm{N}_{\mathrm{i}} \times 4$ populations either to the observed control populations or to the probabilistic distributions of the population endpoints simulated in control conditions. Using the probabilistic distributions of the endpoints in control conditions as a reference is clearly much more discriminating. 


\section{Discussion}

The objective of this study was to test a methodology consisting in modelling the probabilistic distributions of the endpoints of mosquitofish population in control conditions in order to improve the statistical power of mesocosm studies. So, we chose the number of founders as a so-called "stressor" because subsequent consequences at the population level could be expected. It would have been more speculative to have exposed fish to a chemical, because the mode of action of chemicals is rarely fully characterized, with unknown effects and consequences on the population dynamics. During the calibration process of the model a conservative choice was made relative to endpoint variability with the purpose of reducing the risk of concluding that a chemical has an effect when in reality it has none (Beaudouin et al. 2008b). Thus, the calibration process was halted when all simulated values fell into the $95 \%$ bilateral confidence interval of the observed values and most of the endpoints variability was superior or equal to variability assessed from the data. In this study, despite this conservative choice, the statistical power of the data analysis was dramatically improved.

\section{Detected effects are consistent with mosquitofish biology}

Regardless of the statistical method, the increase of the number of founders at the beginning of the experiment was shown to result in a significant increase of both the number of founder females and the mean length of mature males collected at the end of the experiment. The increase of founder females was expected. Main predators of the adult mosquitofish are birds and fish (Britton and Moser 1982). In this mesocosm experiment, these two kinds of predator were absent (nets was installed over the mesocosms and no other fish species was present), hence, a negligible adult fish mortality could be expected (Soubeyrand et al. 2007). Accordingly, increasing the number of founder females had a direct effect on the number of founder females surviving at the end of the experiment. For the males, the comparison of the simulated distribution of the length frequency distributions with the observed length frequency distributions of the $\mathrm{N}_{\mathrm{i}} \times 2$ and $\mathrm{N}_{\mathrm{i}} \times 4$ populations results in a precise interpretation of the increase of the mean length of mature individuals (Fig. 3D). Actually, in the $\mathrm{N}_{\mathrm{i}} \times 2$ and $\mathrm{N}_{\mathrm{i}} \times 4$ populations, males from 17 to $21 \mathrm{~mm}$ were under-represented and males from 22 to $29 \mathrm{~mm}$ were over-represented. Two causes should have interacted to explain these differences. (i) founder males reached male maximal length (in Gambusia holbrooki, median maximal length is $25.0 \mathrm{~mm}$ (Beaudouin et al. 2008a)) and they represented a greater proportion of the mature males in the $\mathrm{N}_{\mathrm{i}} \times 2$ and $\mathrm{N}_{\mathrm{i}} \times 4$ populations than in the control populations at the end of the experiment. (ii) Sexual competition in mosquitofish is known to increase male length at sexual maturity in behaviourally dominated males (Campton and Gall 1988; Zulian et al. 1995). Therefore, the higher number of founder males in $\mathrm{N}_{\mathrm{i}} \times 2$ and $\mathrm{N}_{\mathrm{i}} \times 4$ populations than in control populations result in intensified sexual competition for males maturing during the experiment in these populations (males born during the experiment and mature at the end of the experiment).

The above discussed differences were the only ones to be detected when $\mathrm{N}_{\mathrm{i}} \times 2$ and $\mathrm{N}_{\mathrm{i}} \times 4$ populations were compared to the observed control populations. However, the comparison of the $\mathrm{N}_{\mathrm{i}} \times 2$ and $\mathrm{N}_{\mathrm{i}} \times 4$ populations to the simulated probabilistic distributions of the endpoints in control conditions enables one to detect these differences plus differences for three additional scalar endpoints: the total number of fish, the mean length of founder females, and the coefficient of variation of the juvenile length. Furthermore, the analysis of the length frequency distributions showed significant differences and provided decisive interpretative arguments. 
The additional singularities detected in two scalar endpoints of the $\mathrm{N}_{\mathrm{i}} \times 4$ populations (higher number of fish, smaller size of the founder females) can be logically interpreted as follows. During the first reproductive event, the greater number of founder females in the $\mathrm{N}_{\mathrm{i}} \times 4$ populations likely resulted in a huge offspring recruitment when compared to control. From our data (unpublished) and from literature data (Cabral and Marques 1999; Perez-Bote and Lopez 2005), $30 \mathrm{~mm}$ female mosquitofish give birth to about 30 live, free-swimming offspring. Accordingly, about 720 offspring were expected from the first reproductive event in the $\mathrm{N}_{\mathrm{i}} \times 4$ populations whereas only 180 offspring were expected in the control populations. Consequently, the greater number of founder fish and offspring in the $\mathrm{N}_{\mathrm{i}} \times 4$ populations intensified the density-dependent effects on growth and the depletion of the trophic resources (Botsford et al. 1987; Beaudouin et al. 2008a), thus resulting in a smaller length of the founder females at the end of the experiment. The comparison of the female length frequency distributions (Fig. 3C) also showed that females from 25 to $35 \mathrm{~mm}$ (females from the first reproductive event) were over-represented in $\mathrm{N}_{\mathrm{i}} \times 4$ populations compared to control populations, thus confirming the above arguments. Obviously, the increase of the offspring recruitment also explains the higher number of fish in the $\mathrm{N}_{\mathrm{i}} \times 4$ populations.

In the $\mathrm{N}_{\mathrm{i}} \times 2$ populations, the total number of fish and the mean length of founder females were not significantly different than in the simulated populations. However, the $\mathrm{CV}$ of the juvenile length was higher in the $\mathrm{N}_{\mathrm{i}} \times 2$ populations. One of the two $\mathrm{N}_{\mathrm{i}} \times 2$ populations contained a low proportion of juveniles (221 juveniles, about $50 \%$ of fish in the population), while the other $\mathrm{N}_{\mathrm{i}} \times 2$ population contained 516 juveniles, $70 \%$ of fish in the population, as the other populations of this experiment (Fig. 2D). The low proportion of juveniles in one of the $\mathrm{N}_{\mathrm{i}} \times 2$ populations was caused by a lack of juveniles from 11 to $15 \mathrm{~mm}$ (Fig. 3B). This should explain the significant increase of the $\mathrm{CV}$ of the length of juveniles in the $\mathrm{N}_{\mathrm{i}} \times 2$ populations (Fig. $2 \mathrm{~N}$ ). Interestingly, the mesocosm with a low proportion of juveniles exhibited a macrophyte community different from the other mesocosms (Fig. 1). $\mathrm{pH}$ and dissolved oxygen concentration were also different in this mesocosm (Table 1, $\mathrm{N}_{\mathrm{i}} \times 2-1$ ) suggesting an effect of macrophyte community. As described by several authors (Wainwright et al. 1984; Botsford et al. 1987), a low density of emergent macrophytes does not provide refuge to juvenile from cannibalism. Interestingly, Lemna sp. developed on the top of the water and do not provide refuge for the offspring. Thus, the low proportion of juveniles observed could be due to cannibalism which has indirectly increased the trophic resources for the adults and thereafter, decreased the density-dependent effects on growth. Consequently, the low abundance of juveniles in one $\mathrm{N}_{\mathrm{i}} \times 2$ population could explain the lack of effect of increasing the number of founder individuals on the total number of fish and on the mean length of founder females in the $\mathrm{N}_{\mathrm{i}} \times 2$ populations. The results suggest that this mesocosm was perturbed more by the "nonstandard" dynamics of its macrophyte community than by the treatment (i.e. two times more founders). In the context of our study, which is conducted to demonstrate the added value of our methodology for mesocosm data analysis, this replicate takes on a particular interest. Indeed, the alteration of the fish population dynamics in this mesocosm was detectable only by using our modelling approach.

In the $\mathrm{N}_{\mathrm{i}} \times 4$ populations, the juvenile length frequency distribution presents an overabundance of the length classes from 11 to $15 \mathrm{~mm}$ and a underabundance of the length classes from 8 to $10 \mathrm{~mm}$. Overabundance of the length classes from 11 to $15 \mathrm{~mm}$ is likely due to a higher recruitment. Underabundance of the length classes from 8 to $10 \mathrm{~mm}$ could be due, at least partly, to higher density-dependent effects such as increase of cannibalism and/or higher juvenile mortality due to food limitation. 
Taken altogether, the differences observed on the scalar outputs (Fig. 2) and on the length distributions (Fig. 3) are consistent and can be interpreted based on the literature on mosquitofish population dynamics (Wainwright et al. 1984; Botsford et al. 1987; Drèze et al. 1998; Benoit et al. 2000). The existence of logical and mechanistic explanations for the outputs of the length distributions analysis strongly supports the relevance of the significant differences between the endpoints. Furthermore, this suggests a low rate of false positive results in our analysis.

\section{Statistical power of mesocosm experiment}

When the mean values calculated from $\mathrm{N}_{\mathrm{i}} \times 4$ populations and observed control populations were compared, the mean length of the founder females and the total number of fish exhibited relative differences equal to about $10 \%$ and $60 \%$, respectively (relative difference calculated as $\mid \mu_{\mathrm{Ni} \times 4}-\mu_{\text {Control }} / / \mu_{\text {Control }} \times 100$ ). However, these differences were not significant, although the variability of these two endpoints was relatively low (the coefficients of variation were $10 \%$ and $20 \%$, respectively). The small number of replicates (i.e., three control populations, two $\mathrm{N}_{\mathrm{i}} \times 2$ and two $\mathrm{N}_{\mathrm{i}} \times 4$ populations) should explain this lack of significant difference.

To test our approach in realistic conditions, the number of replicates used in this experiment was similar to that classically used in mesocosm experiments. Indeed, from 17 published mesocosm studies, Sanderson (2002) reported that the mean number of replicates per treatment was 3.5 (from 2 to 5 replicates per study). With this number of replicates, the minimal detectable difference is $35 \%$ with an observed CV of $10 \%$ (mean length of the founder females) and $70 \%$ with an observed CV of $20 \%$ (total number of fish) $(\alpha=0.05, \beta=0.05$ ). Hence, 30 replicates should have been implemented to detect a significant effect on the mean length of the founder females and five replicates to detect effect on the total number of fish. Unfortunately, there is no practicable way to monitor these numbers of mesocosms. On the contrary, as shown in this study, the simulation of the probabilistic distributions of the endpoints in control conditions is a powerful alternative which make possible to reveal significant differences.

Using a population dynamics model to simulate control populations provides new endpoints to compare the populations through the length frequency distributions. Actually, the length frequency distributions constitute a record of the population dynamics, in which each size class provides information on the population and its past dynamics (Uchmanski 1985). Thus, the fifty length classes, which cover the length frequency distribution of the mosquitofish population, could be regarded as approximately fifty different variables (even if they are not independent and, therefore, are partially redundant), thus providing a high discriminatory power when comparing populations.

Comparisons of the observed data or comparisons based on the simulated distributions of the endpoints were performed with 20 independent statistical tests (20 population endpoints). In this case, $95 \%$ confidence interval of a binomial law with a probability equal to 0.05 (type I error) predicts that the number of false positive results varied from 0 to 3 . Hence, in the worst case, statistical analysis based on the simulated control populations could result in three false positive results, while analysis based on the observed populations could result in no false positive results. Even in this worst case, the number of significant differences identified based on the simulated distributions of the endpoints is always higher compared to observed data analysis. 
Globally, the case study presented in this paper suggests that the simulation of the distributions of population endpoints under control conditions decreases the number of false negative results and hence increases the statistical power of the analysis of mesocosm data. We identify two main ways of improvement of our methodology. First, the statistical comparisons of the population endpoints were carried out considering the population endpoints as independent. However, the population endpoints were correlated (Beaudouin et al. 2008b). Taking into account the relationships between the population endpoints should lead to an increase of the statistical power of the comparisons. Second, assessing the minimal difference detectable for the population endpoints using the simulated distribution of the endpoints as reference can turn out to be a precious piece of information. Hence, the increase of statistical power provided by our method could be quantified precisely. It can be performed through simulations, by generating perturbed population data according to a gradient of values for each endpoints.

\section{Population modelling in ecotoxicology}

To our knowledge the use of a mathematical model to define the probabilistic distributions of the endpoints in control conditions had never been proposed to improve the performance of ecotoxicity test in mesocosm. Models are classically used to upscale effects from individual level to population level (Forbes et al. 2009; Forbes et al. 2011). Our model could also be used in this purpose. IBMs are suitable tools to increase the relevance of ecotoxicity test by incorporating the available mechanistic knowledge on the links between responses at the individual level and responses at the population level (Forbes et al., 2008). Predictions for stressed populations could be easily achieved provided dose response relationships are known for the key parameters. To perform this kind of analysis, we must first check if the model developed to simulate populations under control conditions (the current validity domain of our model) is able to simulate stressed populations (other validity domains than the control situation). This topic should be explored in future works.

\section{Conclusion}

An individual-based model of the mosquitofish population dynamics in lentic mesocosm was used to predict the probabilistic distributions of population endpoints under control conditions. In these conditions the statistical power of mesocosm data analysis was dramatically improved. This methodology is currently being applied by our laboratory to assess the effects of chemicals on fish population in mesocosm.

Acknowledgments This work was supported by the "Programme National d'Écotoxicologie" (PNETOX), France. The author acknowledges the support of the French Ministry in charge of Ecology and Sustainable Development for this study, within the framework of Programme 190. We thank G. Bounaut and C. Sévellec for their excellent technical assistance. The authors wish to thank C. Brochot, E. Mombelli, A. Pery, C. Tebby, F. Zeman, so as two anonymous reviewers for their valuable comments on the manuscript. 


\section{References}

Beaudouin R, Ginot V, and Monod G (2008a) Growth characteristics of eastern mosquitofish Gambusia holbrooki in a northern habitat (Brittany, France). J. Fish Biol. 73:2468-2484.

Beaudouin R, Monod G, and Ginot V (2008b) Selecting parameters for calibration via sensitivity analysis: An individual-based model of mosquitofish population dynamics. Ecol. Model. 218:29-48.

Benoit HP, Post JR, and Barbet AD (2000) Recruitment dynamics and size structure in experimental populations of the mosquitofish, Gambusia affinis. Copeia 2000:216-221.

Botsford LW, Vondracek B, Wainwright TC, Linden AL, Kope RG, Reed DE, and Cech JJ (1987) Population development of the mosquitofish, Gambusia affinis, in rice fields. Environ. Biol. Fishes. 20:143-154.

Britton RH, and Moser ME (1982) Size specific predation by herons and its effect on the sex-ratio of natural populations of the mosquito fish Gambusia affinis Baird \& Girard. Oecologia 53:146-151.

Cabral JA, and Marques JC (1999) Life history, population dynamics and production of eastern mosquitofish, Gambusia holbrooki (Pisces, Poeciliidae), in rice fields of the lower Mondego River Valley, western Portugal Acta. Oecol. 20:607-620.

Campton DE, and Gall GAE (1988) Responses to selection for body size and age at sexual maturity in the mosquitofish, Gambusia affinis. Aquaculture 68:221-241.

de Jong FMW, Mensink BJWG, Smit CE, and Montforts MHMM (2005) Evaluation of Ecotoxicological Field Studies for Authorization of Plant Protection Products in Europe. Hum. Ecol. Risk. Assess. 11:11571176.

DeAngelis DL, Cox DK, and Coutant CC (1979) Cannibalism and size dispersal in young-of-the-year largemouth bass: experiment and model. Ecol. Model. 8:133-148.

Drèze V, Gaulay O, and Monod G (1998) Development of mosquitofish (Gambusia affinis holbrooki) populations in lentic mesocosms. Perspectives for ecotoxicological studies. Bull. fr. Pêche Piscic. 350351:465-477.

Dulzetto F (1931) Sviluppo e struttura del gonopodio di Gambusia holbrookii. (Grd.). Pubbl. Stn. Zool. Napoli. 11:62-85.

Forbes VE, Calow P, Grimm V, Hayashi TI, Jager T, Katholm A, Palmqvist A, Pastorok R, Salvito D, Sibly R, Spromberg J, Stark J, and Stillman RA (2011) Adding Value to Ecological Risk Assessment with Population Modeling. Hum. Ecol. Risk. Assess. 17:287-299.

Forbes VE, Hommen U, Thorbek P, Heimbach F, Van den Brink P, Wogram J, Thulke HH, and Grimm V (2009) Ecological models in support of regulatory risk assessments of pesticides: developing a strategy for the future. . Integr Environ Assess Manag 5:167-172.

Giddings JM, Franco PJ, Cushman RM, Hook LA, Southworth GR, and Stewart AJ (1984) Effects of chronic exposure to coal-derived oil on freshwater ecosystems: II. experimental ponds. Environ. Toxicol. Chem. 3:465-488.

Grimm V, Berger U, DeAngelis DL, Polhill JG, Giske J, and Railsback SF (2010) The ODD protocol: A review and first update. Ecol. Model. 221:2760-2768.

Grimm V, and Railsback SF. (2005). Individual-based Modeling and Ecology. Princeton University Press edition, Princeton, New Jersey.

Kennedy JH, Ammann LP, Waller WT, Warren JE, Hosmer AJ, Cairns SH, Johnson PC, and Graney RL (1999) Using statistical power to optimize sensitivity of analysis of variance designs for microcosms and mesocosms. Environ. Toxicol. Chem. 18:113-117.

Kraufvelin P (1999) Baltic hard bottom mesocosms unplugged: replicability, repeatability and ecological realism examined by non-parametric multivariate techniques. J. Exp. Mar. Biol. Ecol. 240:229-258.

Perez-Bote JL, and Lopez MT (2005) Life-history pattern of the introduced eastern mosquitofish, Gambusia holbrooki (Baird \& Girard, 1854), in a Mediterranean-type river: the River Guadiana (SW Iberian Peninsula). Ital. J. Zoolog. 72:241-248.

Pyke GH (2005) A Review of the Biology of Gambusia affinis and G-holbrooki. Rev. Fish. Biol. Fisher. 15:339365.

R Development Core Team. (2009). R: A language and environment for statistical computing. . R Foundation for Statistical Computing, Vienna, Austria.

Sanderson H (2002) Pesticide studies-Replicability of micro/mesocosms. Environ. Sci. Pollut. R 9:429-435.

Shaw JL, and Kennedy JH (1996) The use of aquatic field mesocosm studies in risk assessment. Environ. Toxicol. Chem. 15:605-607.

Shaw JL, Moore M, Kennedy JH, and Hill IR. (1994). Design and statistic alanalysis of field aquatic mesocosm studies. in R. L. Graney, J. H. Kennedy, and J. H. Rodgers, editors.in Aquatic Mesocosm Studies in Ecological Risk Assessment. p. 85-103. Lewis, BocaRaton, Florida33431. 
Soubeyrand S, Beaudouin R, Desassis N, and Monod G (2007) Model-based Estimation of the Link between the Daily Survival Probability and a Time-Varying Covariate, Application to Mosquitofish Survival Data. Math. Biosci. 210:508-522.

Tatara CP, Mulvey M, and Newman MC (2002) Genetic and demographic responses of mercury-exposed mosquitofish (Gambusia holbrooki) populations: Temporal stability and reproductive components of fitness. Environ. Toxicol. Chem. 21:2191-2197.

Uchmanski J (1985) Differentiation and frequency distributions of body weights in plants and animals. Philosophical Transactions of the Royal Society London B 310:1-75.

Wainwright TC, Kope RG, Botsford LW, and Cech JJ (1984) Implications of laboratory mosquitofish experiments for populationd evelopment in rice fields. Proc. Calif. Mosq and Vect. Contr. Assoc. 52:110-114.

Walters LL, and Legner EF (1979) Impact of the desert pupfish, Cyprinodon macularius, and Gambusia affinis affinis on fauna in pond ecosystems. Hilgardia 48:1-18.

Zulian E, Bisazza A, and Marin G (1995) Variations in Male Body-Size in Natural-Populations of Gambusia Holbrooki. Ethol. Ecol. Evol. 7:1-10. 
Figure legends

Fig. 1 Photography of the macrophyte communities at 61 days of experiment.

(A) Mesocosm with a control population (founded by 6 females and 2 males).

(B) The first mesocosm with a population founded by 12 females and 4 males.

(C) The second mesocosm with a population founded by 12 females and 4 males, and which presented a low frequency of juveniles.

(D) Mesocosm with a population founded by 24 females and 8 males.

Diameter of the mesocosm was $3 \mathrm{~m}$. For details about mesocosm design see material and methods section.

Fig. 2 Simulated control populations (CS; $n=10,000)$, observed control populations (CR; $n=3)$, populations founded with two times more individuals $\left(\mathrm{N}_{\mathrm{i}} \times 2 ; \mathrm{n}=2\right)$, and populations founded with four times more individuals $\left(\mathrm{N}_{\mathrm{i}} \times 4 ; \mathrm{n}=2\right)$ as described by 10 endpoints

- the total number of fish (A), the number of founder females (B),

- $\quad$ the percent of juveniles (C), females (D), males (E), mature males among all males (F),

- the mean length of founder females $(\mathrm{G})$, descendant females $(\mathrm{H})$, juvenile $(\mathrm{I})$, mature males $(\mathrm{J})$, immature males $(\mathrm{K})$.

- the CV of the length of founder females (L), descendant females (M), juvenile (N), mature males (O), immature males $(\mathrm{P})$.

All endpoints refer to population size and structure at the end of the experiment. Two groups of data labelled with different lower case letters have significantly different value.

Fig. 3 Fish length frequency distributions in the observed populations founded with two $(\mathrm{Ni} \times 2)$ and four $(\mathrm{Ni} \times 4)$ times more individual than in control populations and probabilistic distributions of the length frequency distributions in the simulated populations in control conditions (population structure at the end of the experiment).

(A) Populations length frequency distribution. (B) Juvenile length frequency distribution. (C) Female length frequency distribution. (D) Male length frequency distribution. The real control populations are not presented to avoid over complexity of this Figure. It was published as Figure 7 in Beaudouin et al. (2008b).

Reading guide:

- White full lines represent the length frequency distribution of the two observed $\mathrm{N}_{\mathrm{i}} \times 2$ populations.

- Black full lines represent the length frequency distribution of the two observed $\mathrm{N}_{\mathrm{i}} \times 4$ populations.

- Colour level represents the frequency of simulated populations $(n=10,000)$ having a given percentage of individuals for a given class length.

- In the observed populations represented by the white line, $15-16 \mathrm{~mm}$ fish represent $10 \%$ of all the fish. 
- The populations with $10 \%$ of their fish measuring $15-16 \mathrm{~mm}$ are nearly $5 \%$ (light blue-green level) of the 10,000 simulated populations.

- The populations with $1 \%$ of their fish measuring $29-30 \mathrm{~mm}$ represented nearly $25 \%$ (light orange level) of the 10,000 simulated populations.

\section{TABLE}

Table 1 Physico-chemical parameters recorded weekly in the mesocosms (mean \pm standard deviation calculated on the whole dataset)

\begin{tabular}{cccccccc}
\hline Mesocosm & Control-1 & Control-2 & Control-3 & $\mathrm{N}_{\mathrm{i}} \times 2-1$ & $\mathrm{~N}_{\mathrm{i}} \times 2-2$ & $\mathrm{~N}_{\mathrm{i}} \times 4-1$ & $\mathrm{~N}_{\mathrm{i}} \times 4-2$ \\
\hline Water temperature & $21.5 \pm 3.6$ & $21.5 \pm 3.4$ & $21.7 \pm 3.6$ & $21.3 \pm 3.4$ & $21.8 \pm 3.4$ & $21.5 \pm 3.3$ & $21.4 \pm 3.5$ \\
$\mathrm{O} 2(\mathrm{mg} / \mathrm{l})$ & $11.8 \pm 2.3$ & $11.2 \pm 2.9$ & $11.0 \pm 1.9$ & $8.6 \pm 1.7$ & $11.6 \pm 2.3$ & $11.3 \pm 2.1$ & $11.4 \pm 1.6$ \\
$\mathrm{O} 2(\%)$ & $123.6 \pm 24.5$ & $113.5 \pm 29.1$ & $119.8 \pm 24.3$ & $92.9 \pm 17.6$ & $120.2 \pm 23.1$ & $118.7 \pm 23.6$ & $123.7 \pm 18.3$ \\
$\mathrm{pH}$ & $9.9 \pm 0.3$ & $9.9 \pm 0.3$ & $9.9 \pm 0.5$ & $8.9 \pm 0.7$ & $9.9 \pm 0.3$ & $9.9 \pm 0.5$ & $10.1 \pm 0.3$ \\
\hline
\end{tabular}


Table 2 Significant differences when comparing the population founded with more individuals either to the observed control populations or to the simulated probabilistic distributions of the endpoints in control conditions.

\begin{tabular}{lll}
\hline Population endpoints & Populations $\mathbf{N}_{\mathbf{i}} \times \mathbf{2}$ & Populations $\mathbf{N}_{\mathbf{i}} \times \mathbf{4}$ \\
\hline Fish number & Total & Founder females \\
\hline Frequency & Females \\
& Juvenile \\
& Immature males \\
& Mature males \\
\hline Mean length & Founder females \\
& Descendant females \\
& Juvenile \\
& Immature males \\
& Mature males \\
\hline CV of the length & Founder females \\
& Descendant females \\
& Juvenile \\
Imgth frequency distributions & Total \\
& Female \\
\hline & Juvenile \\
\hline & Male \\
\hline
\end{tabular}

Crossed cell: SIGNIFICANT DIFFERENCE observed comparing the $\mathrm{N}_{\mathrm{i}} \times 2$ or $\mathrm{N}_{\mathrm{i}} \times 4$ populations to the observed control populations

Grey cell: SIGNIFICANT DIFFERENCE observed comparing the $\mathrm{N}_{\mathrm{i}} \times 2$ or $\mathrm{N}_{\mathrm{i}} \times 4$ populations to the simulated probabilistic endpoints distributions in control conditions.

Populations $\mathrm{N}_{\mathrm{i}} \times 2$ : populations founded with two times more individuals ( 12 females and 4 males) than in control populations Populations $\mathrm{N}_{\mathrm{i}} \times 4$ : populations founded with four times more individuals ( 24 females and 8 males) than in control populations 


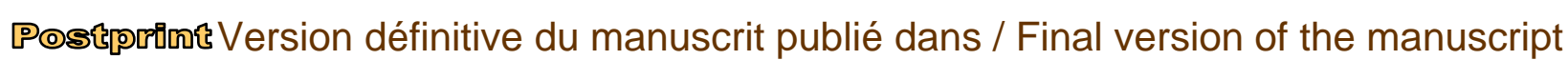
published in : Ecotoxicology 2012, 21 (1) : 155-164
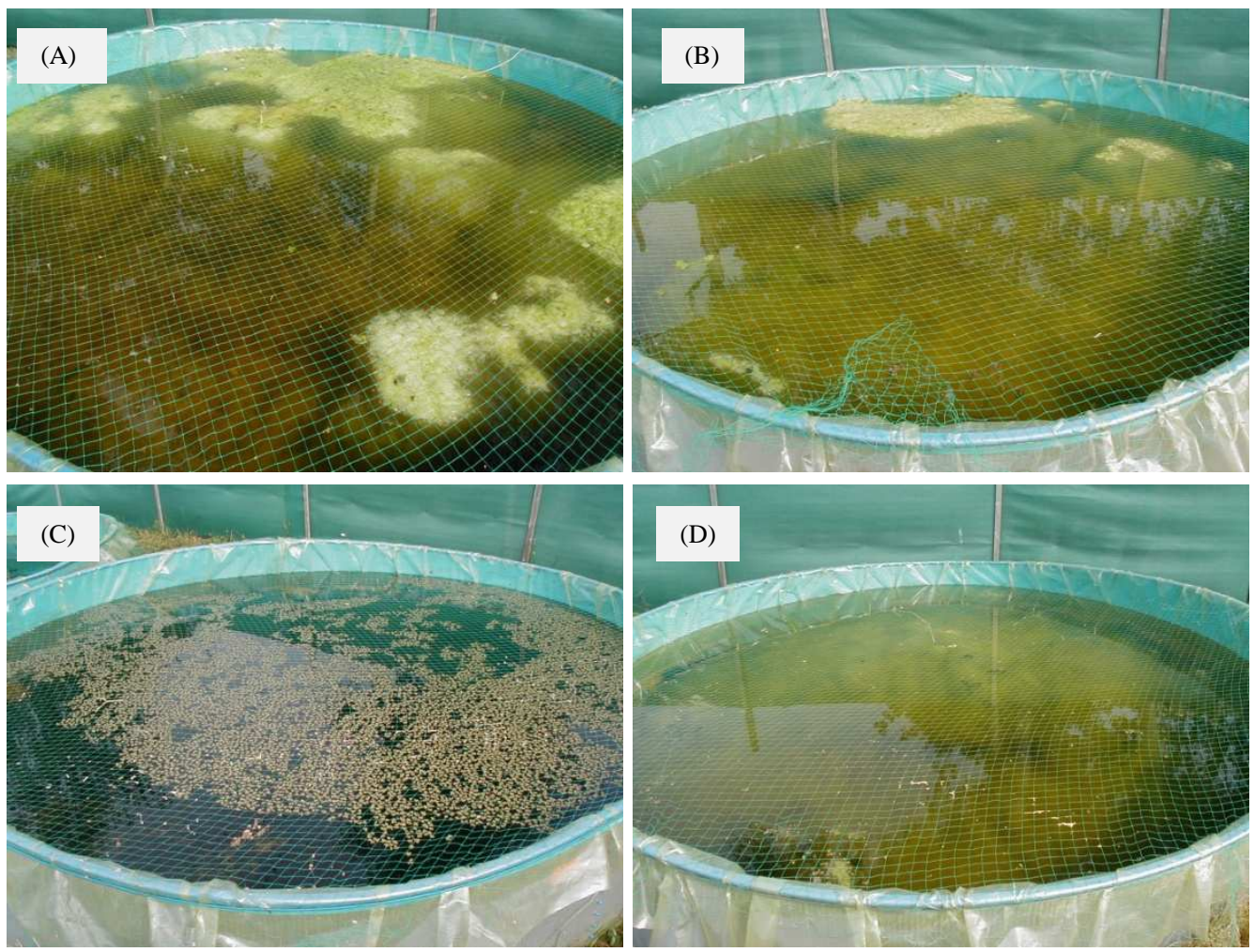

Fig. 1. 


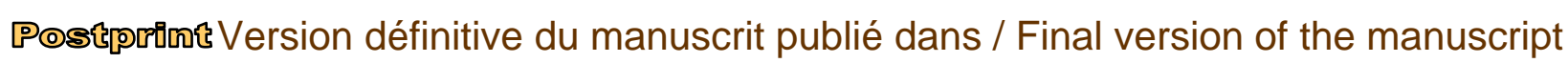
published in : Ecotoxicology 2012, 21 (1) : 155-164
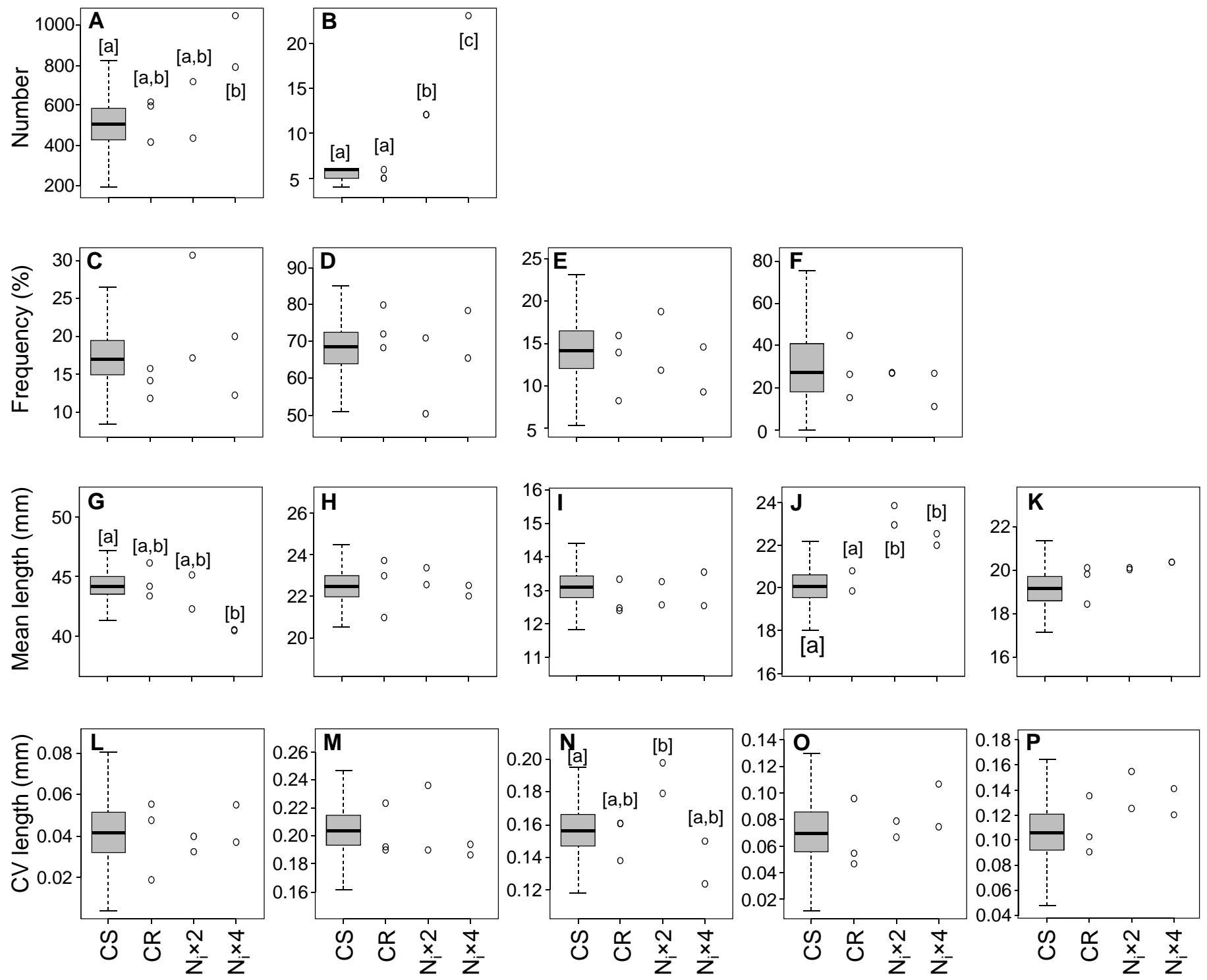

Fig. 2. 


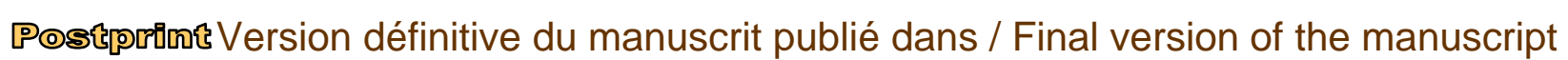
published in : Ecotoxicology 2012, 21 (1) : 155-164
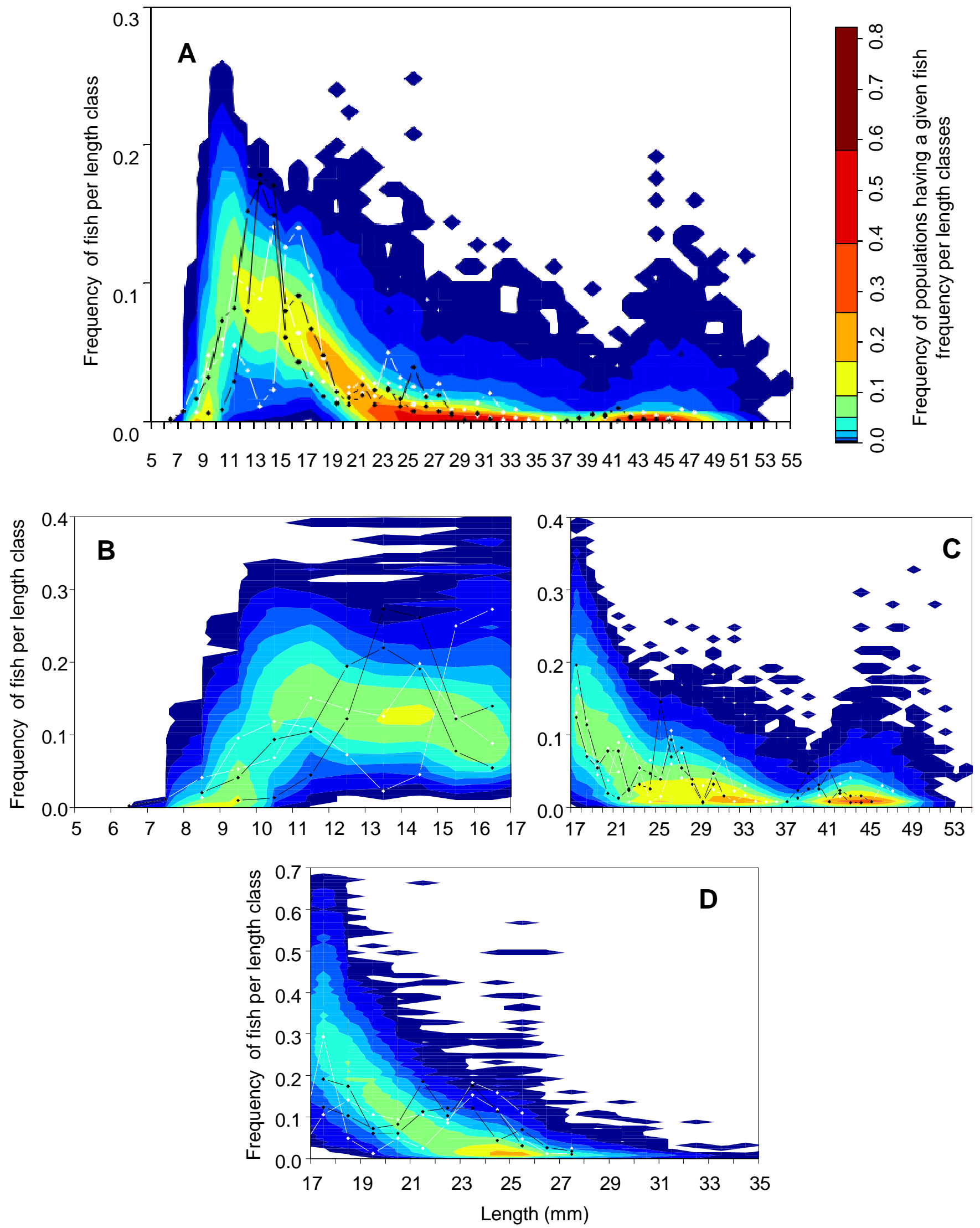

Fig. 3. 


\section{Electronic Supplementary Material}

\section{Statistical comparisons}

In the case of a scalar output, $i$ denotes this output, $j$ the experiment, $f_{i}$ the probabilistic distribution given by the N1 replication of the model for this output and $F_{i}$, the cumulative probability function of $f_{i}$. Then, the probability $p_{i, j}$ of a value $x_{j}$ of an output $i$ of an experiment $j$ of belonging to the simulated control distribution of output $i$ is given by (bilateral test):

$$
\begin{array}{ll}
p_{i, j}=2 \times F_{i}\left(x_{j}\right) & \text { if } F_{i}\left(x_{j}\right)<0.5 \\
p_{i, j}=1-\left(2 \times F_{i}\left(x_{j}\right)\right) & \text { if } F_{i}\left(x_{j}\right)>0.5
\end{array}
$$

If an experiment is replicated, say $\mathrm{n}$ times, the probability of an $\mathrm{n}$-replicated output of being distributed according to the simulated control population can no longer be directly computed from $F_{i}$, and a likelihood test must be used. As replications are independent, the likelihood is the product of the $n$ unitary probabilities $p_{i, j}$. Hence, the likelihood $\left(L_{i}\right)$ of a vector of $n$-replicated values $\left(x_{1}, \ldots, x_{n}\right)$ of an output $i$ of being distributed according to its simulated control distribution is given by:

$$
L_{i}=\prod_{j=1}^{n} p_{i, j}
$$

The likelihood test consists of comparing this $L_{i}$ value to the distribution of $L_{i}$ under the null hypothesis, i.e. "The $n x_{j}$ are all distributed according to the control distribution $F_{i}$ ". But this likelihood distribution is unknown, and to provide an estimate of it, $\mathrm{N} 2=10000$ samples of $n$ values were randomly drawn from $f_{\text {i }}$, hence simulating $10000 n$-independently-replicated control outputs $i$. The likelihood of these N2 samples is then computed according to Eq. (31), providing a cumulative probability function of $L_{i}$ that we can denote $F L_{i}$. Then, the probability of an $n$-replicated output $i$ to be distributed according to the simulated control population can be computed according to Eq. (30), with $F_{i}\left(x_{j}\right)$ replaced by $F L_{i}\left(L_{i}\right)$.

Non scalar (distribution) comparisons

In the case of a non scalar output, the simulated reference was also given by the set of $\mathrm{N} 1=10000$ simulated control populations. This provided a probabilistic distribution of each value of the output distribution $i$. This distribution is referred to as a probability distribution of distribution $\left(f d d_{i}\right)$ empirically introduced and developed by Vrac et al. (2004). To understand what a fdd is, let us consider the case where output $i$ represents the length distribution of the fish population at the end of the experiment $j$. Let us now split this length distribution into $k$ classes of $1 \mathrm{~mm}$ for example, and denote $k$ as one of these classes. We can now denote $f_{i, j, k}$ as the frequency of class $k$ in the population $j$ for output $i$ : $f$ can be null if no fish belongs to $k$, and up to one if all fish belong to $k$ (i.e. all fish of the population $j$ have the same length $k$ ). With these notations, the fdd expresses the frequency of $f_{i, j, k}$ in the 10000 simulated populations, hence, fdd is a frequency of frequency. The comparison method is now similar to the one presented for scalar endpoints (section 4.3.1). The probability $p_{i, j, k}$ of the frequency $f_{i, j, k}$ of class $k$ of population $j$ for output distribution $i$ to be distributed according to the simulated $f d d_{i}$ is given by Eq. (30) with Fi representing the cumulative $f d d$ and $x_{j}$ representing $f_{i, j, k}$. As a given population $j$ is constituted of $k$ 
classes, we can compute the pseudo-likelihood of this population to be distributed according to the simulated $f d d_{i}$ as the product of the probability $p_{i, j, k}$ for all $K$ classes:

$$
P L_{i, j}=\prod_{k=1}^{k} p_{i, j, k}
$$

Note that $P L_{i, j}$ is called a "pseudo" likelihood here, since probabilities are not independent. As the distribution of $P L_{i, j}$ under the null hypothesis is unknown, it is estimated by computing the likelihood of 10000 simulated control distributions. Then, the probability of a distribution $j$ to be distributed according to the control populations is given by Eq. (30), with $F_{i}$ representing the cumulative probability function of $P L_{i, j}$ under the null hypothesis, and $x_{j}$ representing the pseudo-likelihood of population $j$.

For n-replicated populations, just as in "Scalar comparisons" section (3.1), we can compute a global pseudolikelihood as the product of the pseudo-likelihoods of each population.

$$
G P L_{i}=\prod_{j=1}^{n} P L_{i, j}
$$

Then, the probabilistic distribution of $G P L_{i}$ under the null hypothesis must be estimated, by randomly drawing 10000 samples of $n$ independent simulated control populations. For each n-replicated sample, the global likelihood of these samples is computed according to Eq. (33), and the resulting cumulative probability function can be used to compute the probability of a n-replicated distribution of belonging to the simulated control distributions according to Eq. (30): $F_{i}$ now represents the cumulative probability function of $G P L_{i}$ under the null hypothesis, and $x_{j}$ the pseudo-likelihood $G P L_{i}$ of the n-replicated distribution.

\section{References}

Vrac, M., Diday, E., Chédin, A., 2004. Décomposition de mélange de distributions et application à des données climatiques. Rev. Statist. Appl. LII, 67-96. 